\title{
Case 14
}

\section{Sustainable tourism growth: Tanna Island, Vanuatu}

Summary

Key messages
This chapter examines how tourism growth on Tanna Island could be guided sustainably, and what kinds of governance arrangements need to be in place to support this process. It also discuss the necessary monitoring and measuring frameworks that could be used to support a sustainable tourism growth plan, and the array of stakeholders who should be involved in the governance processes. The lessons from Tanna Island could inform other Small Island Developing States (SIDs) that are facing rapid tourism development.

$\begin{array}{lll}\text { Keywords } & - & \text { Tanna Island } \\ & - & \text { Natural ecosystems } \\ & - & \text { Economic benefits } \\ - & \text { Policy development } \\ - & \text { Education and training }\end{array}$

- $\quad$ Tourism is often seen as a way to boost both the formal and informal economies, and to offer new livelihoods, which in turn may reduce the pressure on natural ecosystems.

- Tourism also contributes to serious impacts and exacerbates vulnerability to climate change.

- $\quad$ Planning and policy development on all government levels, training and education can resolve the crisis and promote sustainable tourism development.

\section{C14.1 Introduction}

In the Pacific island states and territories, tourism is the only economic sector to grow relatively consistently over recent years. In the Pacific, there is a growing awareness of the need to develop tourism in a sustainable manner, and of being realistic about the constraints. Some of these constraints relate to difficulty in developing infrastructure and services across a large number of remote low-lying islands, lack of sector-specific information on weather and climate trends, ${ }^{1}$ high population growth rates exerting increasing pressure on the existing natural resources, high levels of poverty, lack of education and skills, ${ }^{2}$ and complex governance structures.

1 Nalau, J.; Becken, S.; Noakes, S. and Mackey, B. (2017), 'Mapping tourism stakeholders' weather and climate information seeking behaviour in Fiji', Weather, Climate and Society, in press.

2 Hay, J.E.; Forbes, D.L. and Mimura, N. (2013), 'Understanding and managing global change in small islands', Sustainable Science, volume 8, issue 3, pp. 303-308.

Kuruppu, N. and Willie, R. (2015), 'Barriers to reducing climate enhanced disaster risks in Least Developed Country-Small Islands through anticipatory adaptation', Weather and Climate Extremes, volume 7, pp. 72-83. 
Pacific islands are vulnerable to cyclones, flooding, drought, tsunamis, volcanic eruptions, and other biophysical hazards. ${ }^{3}$ Such extreme events cannot only destroy the physical resources on which tourism depends (including built assets), ${ }^{4}$ but also damage the reputation and image of the destination. ${ }^{5}$ Extreme events increase operational costs, ${ }^{6}$ and can lead to business disruption. In this context, encouraging tourism development can be challenging, especially when the rules and governance systems to regulate the industry (directive capacity) are not in place or are insufficiently enforced (directive effectiveness). ${ }^{7}$ Considering the projected effects of climate change in island destinations, these challenges are likely to increase. ${ }^{8}$

Tanna Island is the most populous island (about 30,000 people) in the Tafea Province, Vanuatu, located south of Port Vila. Tanna provides an example of many of these complex issues, as it is on the cusp of rapid tourism growth. This case discusses the challenges relating to fostering tourism on a remote island, which, in addition to constraints common to SIDS, also faced significant development setbacks in 2015, when it was devastated by Tropical Cyclone Pam. We then discuss how some of the emerging tourism trends on Tanna Island could lead to sustainable tourism growth, and the role governance plays in enabling a more just and equal approach to development.

\section{C14.2 Tourism on Tanna Island}

Most tourists travel to Tanna Island from Port Vila for a day trip using a local air link to see the Yasur volcano, which erupts every five minutes. Tourists typically spend on average 3.9 nights at Tafea province. ${ }^{9}$ The accommodation sector is only slowly developing, with main resorts on the west side of the island, and with further local accommodations closer to the volcano on the east side in Lenakel. The current linkages between local communities and the tourism industry are relatively undeveloped, except from tourists utilizing roadside stalls and the main market in Lenakel, and the tours on offer on the island. Most resorts source their produce from Port Vila given the limited availability, consistency and quality of local produce. Employees are likewise often sourced from Port Vila given the lack of tourism training programmes on Tanna.

The challenges of sustainable tourism, governance and the impacts of extreme events in Vanuatu, and on Tanna Island in particular, are best understood by looking at the example of Tropical

3 Becken, S.; Mahon, R.; Rennie, H. and Shakeela, A. (2014), 'The Tourism Disaster Vulnerability Framework: An application to tourism in small island destinations', Natural Hazards, volume 71, issue 1, pp. 955-972.

Nalau, J.; Becken, S.; Noakes, S. and Mackey, B. (2017).

4 World Tourism Organization and United Nations Environment Programme (2008), Climate Change and Tourism - Responding to Global Challenges, UNWTO, Madrid.

5 Jeuring, J. and Becken, S. (2013), 'Tourists and severe weather - An exploration of the role of 'Locus of Responsibility' in protective behaviour decisions', Tourism Management, volume 37, pp. 193-202.

6 Becken, S. and Hay, J. (2012), Climate Change and Tourism: from Policy to Practice, Routledge, New York, pp. 31-54.

7 World Tourism Organization (2013a).

8 Becken, S. and Hay, J. (2012).

Uyarra, A.; Cote, I.; Gill, J.; Tinch, R.; Viner, D. and Watkinson, A. (2005), 'Island-specific preferences of tourists for environmental features: Implications of climate change for tourism-dependent states', Environmental Conservation, volume 32, issue 1, pp. 11-19.

9 Vanuatu National Statistical Office (2016), November 2016 tourism highlights (online), available at: http://vnso.gov.vu (04-05-2017). 
Cyclone Pam (hereafter TC Pam). TC Pam hit on 13 March 2015 and caused significant negative impacts on Vanuatu's environment and society, with significant implications on economic development pathways. ${ }^{10}$ Two factors contributed to the magnitude of the impacts: extensively damaged infrastructure and travel warnings. The Port Vila international airport - the main gateway for travellers - was damaged significantly and the first flights to Vanuatu after TC PM were restricted to providing disaster aid supplies. Passenger travel was terminated at least for the first month. Furthermore, three main hotels based in Port Vila received extensive damages and closed down, having to let go off their staff. In addition to these direct impacts, both the Australian and New Zealand Governments issued official travel warnings to deter tourists from travelling to Vanuatu. This led to mass cancellations of travel to Vanuatu, which had severe implications for the national tourism industry. These cancellations impacted all islands, even those that incurred minimal damage from the cyclone, such as Santo north of Port Vila. Tanna was worst affected of all the islands: TC Pam damaged approximately $60-80 \%$ of community structures, including livestock, infrastructure and crops. ${ }^{11}$ Since the tourism industry in Tanna is not yet well developed the direct impact on tourism-based livelihoods was low.

Vanuatu is a popular cruise ship destination and changes in cruise itineraries can have far reaching impacts. Vanuatu's tourism market is dominated by cruise ship visitors (figure C14.1), which is an unusual situation compared with most other destinations. In 2015, and in response to the devastation shown in the media in the aftermath of TC Pam, the cruise ship companies took Vanuatu (Port Vila) off their destination schedules for several months. The drop in arrivals particularly impacted the many small and medium enterprises (taxi and bus drivers, tour operators, restaurants, handicraft sellers) that depend on tourism as their main livelihood. The tourismbased livelihood was suddenly not viable at a time when people needed finances to re-build their homes. ${ }^{12}$ While the cruise ships do not stop on Tanna island, the remittances that Tannese people based in Port Vila can send to the island are impacted by such a tourism decline, highlighting the far-reaching implications that both the cyclone (i.e. impacts in Tanna) and undifferentiated media coverage (i.e. showing 'Vanuatu') can have on local communities. Figure C14.1 also shows that tourism numbers have begun to recover in 2016.

10 Handmer, J. and Iveson, H. (2017), 'Cyclone Pam in Vanuatu: learning from the low death toll', Australian Journal of Emergency Management, volume 32, issue 2, pp. 60-65.

Nalau, J.; Handmer, J. and Dalesa, M. (2017), 'The role and capacity of government in a climate crisis: Cyclone Pam in Vanuatu', in: W. Leal Filho (Ed.), Climate Change Adaptation in Pacific Countries: Fostering Resilience and Improving the Quality of Life, Springer, Berlin.

11 Tafea Provincial Disaster Committee and CARE International (2015), Lessons Learnt from Tropical Cyclone Pam for Tafea Provincial Disaster Committee, Tafea Provincial Disaster Committee and CARE International, Republic of Vanuatu.

12 Nalau, J.; Handmer, J. and Dalesa, M. (2017). 
Figure C14.1 Total tourist arrivals by air and cruise ship in Vanuatu, 2001-2016

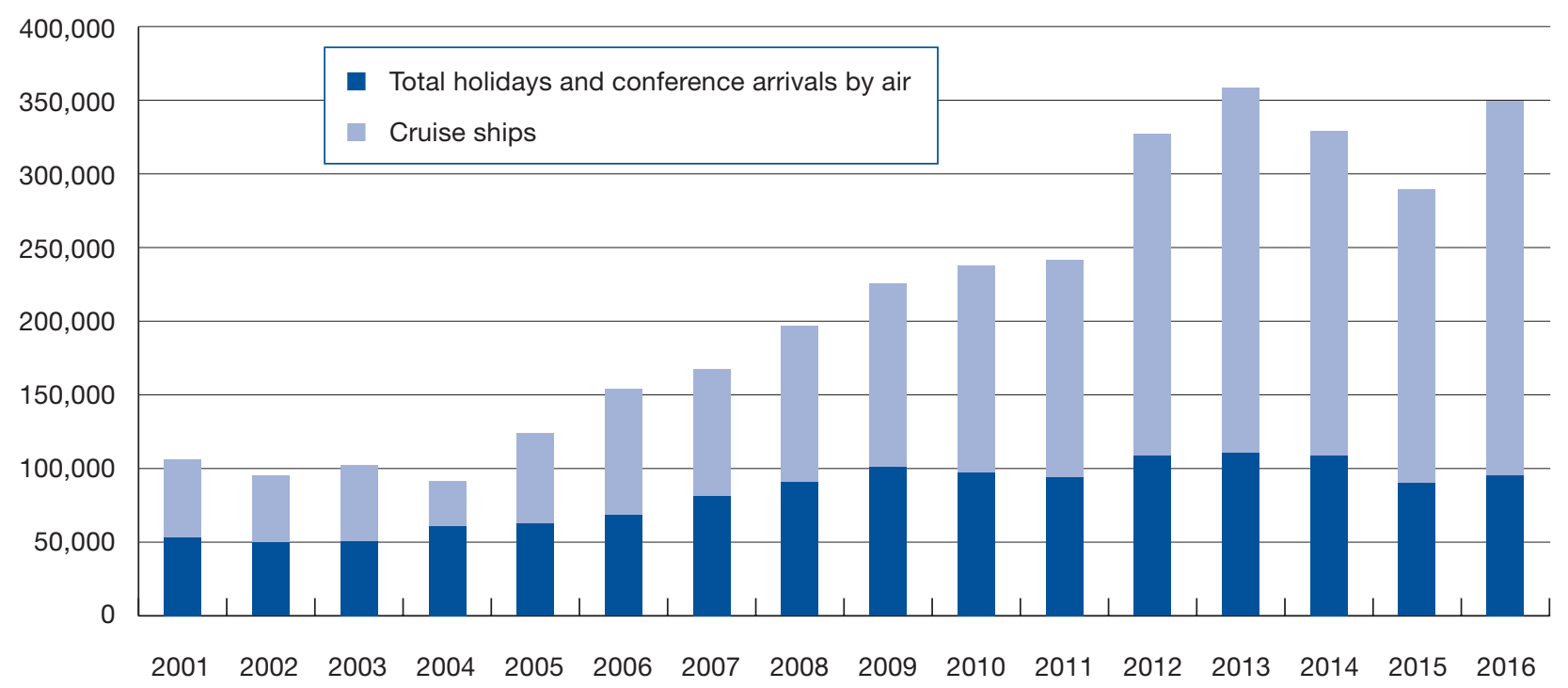

Source: Vanuatu National Statistical Office (2016), November 2016 tourism highlights (online), available at: http://vnso.gov.vu/ (04-05-2017).

\section{C14.3 Vanuatu's tourism policy context and future prospects of tourism on Tanna}

In December 2013, the Ministry of Tourism, Industry, Commerce and Ni-Vanuatu Business released the most recent Vanuatu Strategic Tourism Action Plan (VSTAP), replacing previous tourism master and action plans. The plan identifies priority goals and targets aimed at improving Vanuatu's competitiveness as a destination and to ensure an enhanced distribution of the sectors' benefits to different community groups ${ }^{13}$. The VSTAP is guided by the country's Trade Policy Framework (2012), which highlights the economic importance of tourism for Vanuatu, ${ }^{14}$ as well as the Priorities and Action Agenda for Vanuatu 2006-2015 (PAA), which aims to achieve development improvements as outlined in the UN Millennium Development Goals. The National Sustainable Development Plan (NSDP), released in late 2016, now also supports these policies. ${ }^{15}$ The majority of these plans do not have a legal status excepting that the regulation of foreign investment under the Foreign Investment Promotion Act and Environmental Impact Assessments are required by certain types of developments as defined in the Environmental and Conservation Act.

Current development issues related to tourism are identified in the plan, including little consideration of sustainability in decision making and planning: "There is no emphasis on managing growth of the tourism market, the safety of consumers and the environment that tourism depends on or on addressing poverty alleviation through tourism development". ${ }^{16}$ Hence, one of the principles of

13 Department of Tourism Vanuatu (2013), Vanuatu Strategic Tourism Action Plan 2014-2018, Ministry of Tourism, Industry, Commerce and Ni-Vanuatu Business, Port Villa.

14 Vanuatu Government (2012), Trade Policy Framework, National Advisory Board on Climate Change and Disaster Risk Reduction, Port Vila.

15 Republic of Vanuatu (2016), National Sustainable Development Plan (NSDP), Office of the Prime Minister, Republic of Vanuatu, Port Vila, Vanuatu.

16 Department of Tourism Vanuatu (2013). 
the plan states that "Vanuatu Tourism is an inclusive sustainable industry (economically, socially, culturally and environmentally)"17.

Some of the actions identified in the VSTAP clearly address the need for sustainable economic, social, cultural and environmental outcomes, for example ensuring tourism development is complying with guidelines of environmental and social impact reports (medium priority), increasing the economic linkages from tourism through import substitution for example (medium priority), and supporting small tourism businesses by providing advisory services (medium priority). However, sustainability is not named as a key factor for consideration when prioritising activities listed in the plan. The majority of activities focus on an increase of investment, the development or upgrade of infrastructure and marketing activities with a focus on Australia, New Zealand and New Caledonia.

Following the VSTAP, tourism plans were developed for some of the provinces, including the Tafea Tourism Plan, which applies to Tanna Island. ${ }^{18}$ The Tafea Tourism Plan is a non-legislative strategy that outlines the provincial aspirations for how to manage tourism. In comparison to the national tourism vision, the vision developed for the Tafea Tourism Plan has a strong focus on sustainability, aiming the region to be a "sustainable role model in terms of 'best quality' visitor experience" 19 . This is to be achieved by developing sustainable ecotourism providing economic benefits, while at the same time protecting both culture and the environment and fostering infrastructure and human resource development. ${ }^{20}$ The tourism plan has been developed in cooperation with local stakeholders and acknowledges the importance of local customs. Tafea province aims to attract so-called immersion travellers and has identified the following four market segments: "ecotourism, the adventure market, cruise ships and yachts" ${ }^{21}$. No further evidence was provided on how to identify immersion travellers and why, for example, cruise ship visitors were classified as such. The plan does not directly address disaster risk reduction in its current form, which in particular after TC Pam should be a focus to strengthen the resilience of the sector. Ignoring risk and crises management is a major shortcoming, as disasters can "threaten the very existence of tourism, whether sustainable or not" as they "completely undermine the efforts that go into improving the sustainability of tourism"22.

Both sustainable tourism and risk mitigation relate closely to infrastructure investment, planning and management. The planning of infrastructure is strongly linked to governing tourism growth as it determines not just accessibility to outer islands but also the type of tourists able to access certain areas. The importance of improved infrastructure for tourism development is also visible in Tafea's tourism plan, listing several airline, land and sea access needs. In Tanna, several larger development projects are currently on the way or at the concept stage, including the construction of an international airport as well as the proposal for a cruise ship terminal. When planning large infrastructure developments, it is important that the full range of impacts are being assessed carefully, including what type of tourists these developments provide access to. This will ensure

17 Department of Tourism Vanuatu (2013).

18 Department of Tourism Vanuatu (2011), Tafea Tourism Plan 2011, Ministry of Tourism, Industry, Commerce and Ni-Vanuatu Business, Port Villa.

19 Ibid., p. 10.

20 lbid.

21 Ibid., p. 22.

22 Becken, S.; Mahon, R.; Rennie, H. and Shakeela, A. (2014). 
that the developments are linked to achieving the aims set out in the tourism plan such as attracting "immersion travellers".

Following one of the action items of the VSTAP, the Department of Tourism Vanuatu (DoT) is currently implementing a Vanuatu Tourism Accreditation, the first national accreditation programme for tourism operators. The programme has been developed with the assistance of Ecotourism Australia and in consultation with the Vanuatu Tourism Standards Committee (members are representatives from tourism associations, industry sector and relevant Government agencies. ${ }^{23}$ It sets a minimum operational standard required from all tourism businesses and provides selfassessment forms for 21 tourism sectors. At this stage, the criteria focus mainly on the quality of the tourism product rather than on sustainability obligations, which highlights the early development stage of the wider tourism industry. The assessment of compliance with the criteria is conducted by the DoT by reviewing the checklist answers; there is no information on third party verification audits. If satisfactory, the business will receive its tourism permit from the DoT, which is needed in order to apply for a Business Licence at the Custom/Provincial Government level which is then issued by the Department of Customs and Inland Revenue.

This programme is seen as a step in the right direction of monitoring tourism operators' performance at a national level. Once the programme has been fully implemented and an increase in quality standards has been achieved, a number of sustainability criteria should be added to enhance the sustainability performance of individual operators. As part of this process, it may be useful to increase obligations for larger organizations often owned by foreign investors and assistance and supporting resources should be provided to guide organizations through the sustainability criteria. Monitoring sustainability indicators at an operational level will not just provide benefits nationally but will be important to successfully implement the Tanna Tourism Plan.

\section{C14.4 Discussion}

As an emerging destination expecting an increase in visitation over the coming years, Tanna island has a small window of opportunity to put a framework in place at regional level that ensures the local tourism industry is developed sustainably without compromising damage to its cultural and natural heritage. Such a regional destination framework would need to be developed with public (governmental) and private (tourism businesses) stakeholders and guided and enforced by a national authority such as the Ministry of Tourism, Industry, Commerce and Ni-Vanuatu Business. The Global Sustainable Tourism Council (GSTC) provides guiding principles for destinations in form of Destination Criteria that any tourism destination should aspire to in order to achieve sustainable economic, social, cultural and environmental outcomes ${ }^{24}$. The GSTC criteria were developed as a response to the United Nation's Millennium Development Goals and are addressing the same broad development challenges Vanuatu is aiming to overcome, in particular, poverty alleviation, gender equity and climate change. The management and monitoring of sustainability performance of the destination itself can also be done by joining a GSTC approved programme such as EarthCheck, which provides benchmarking and third party certification options.

23 Spooner, J (2014), Vanuatu Tourism Accreditation Information Pack, Department of Tourism Vanuatu, Port Villa.

24 Global Sustainable Tourism Council (2013), Global Sustainable Tourism Council Criteria for Destinations (GSTC-D), version 1.0 (online), available at: www.gstc.org (21-03-2017). 
How the criteria are applied to Tanna, and what sustainability initiatives or programmes are to be implemented can be defined through the development of the framework, however, they should build on the strategic direction the Tafea Tourism Plan provides. In order to ensure the criteria are implemented effectively and to enhance the positive effects of sustainability programmes and initiatives, it is recommended that the destination authority monitors development, sustainability, and quality of tourism products and services by using relevant indicators and reports upon those publically. There are other issues to consider as well, which we briefly cover here: attracting the right type of tourists, impact of governance on tourism, and training and capacity building.

\section{C14.4.1 Attracting the right type of tourists}

Tanna Island is at the beginning of potentially rapidly increasing tourism development and this presents an important opportunity to invest into sustainable tourism and governance. Tanna as a destination has a unique tourism product, with beautiful unspoilt environment, interesting cultures, and one of the best accessible volcanoes in the world. Demand for such 'off the beaten track' destinations is globally growing, and Tanna is well placed to take advantage of this trend. Sustainable tourism growth could for example focus on creating tourism products, which are compatible with local customs, culture and the environment. It is important to identify the kind of tourists Tanna should be attracting, and the kinds of travel options that exist to reach the island. Increasing foreign mass tourism, in particular from China with direct flights to Tanna, would have a drastic impact on the current structure of the industry and communities. Mass tourism is unlikely to benefit the smaller tourism establishments, which offer more local style accommodation and services. Thus, marketing, product development, infrastructure projects and accessibility need to work hand in hand.

For example, the existing resorts (both high-end and low-end providers) could be asked to take into consideration more sustainable practices such as installing septic water tanks and sewage treatment systems, inform the guests of the use of water on the island, focus on food linkages with local providers (which would reduce waste packaging and provide more stable income for farmers), and expanding the activities on offer in a manner which could also benefit communities on whose land such activities are undertaken. Marketing strategies should then support this sustainable form of tourism by attracting the type of tourists who appreciates this type of experience, such as adventure or conscious traveller.

\section{C14.4.2 Governance and foreign investment}

There are several best practice tourism models, such as that in Bhutan that have managed to develop high yield tourism within limits. ${ }^{25}$ The Government of Bhutan recognizes that "tourism must be environmentally and ecologically friendly, socially and culturally acceptable and economically viable" in order to positively contribute to people's well-being and happiness. Such models could provide strategic direction for the Tafea province on how to manage the tourism growth in sustainable and equitable terms. Yet, the governance structures are complex and influence how decisions can be made on managing coral reefs, beaches, and forests, which all function 
as attractions for tourism. The difficulty in identifying kastom owners of the land and competing land ownership claims on Tanna is an issue, which can reduce potential benefits accruing from tourism. Agreement on the general vision for Tanna tourism therefore is imperative as different visions ultimately result in favouring different governance arrangements and strategies to bring tourists to the island.

There is also a need for the national and provincial governments to regulate the emerging sector in a more streamlined fashion, which could provide different rules for low-end (local bungalows) to the higher end (international standard resorts) based on their financial capability to undertake such improvements. This is something that the Tafea Tourism Plan for instance needs to take into account. There is also a need to look at how regulations and policies are enforced, and to what extent they are inclusive of the diversity of stakeholders who all influence what tourism looks like on the ground on Tanna.

At this point in time where the investments in particular from Chinese are beginning to manifest themselves on the island, it is important that local benefits are considered from tourism operations, and how local communities in particular could benefit from tourism activities. At the national level, Chinese influence is predicted to grow as the Prime Minister of Vanuatu has signed a strategic cooperation framework with the HNA Tourism Group of China. ${ }^{26}$ The extent that the Chinese tourism investments can be governed and linked with existing initiatives and regulations is crucial as otherwise these flows and investments might end up benefiting only few operators and could potentially lead to unsustainable development of the industry.

Often Pacific Islands are heavily dependent on external aid and private sector investments, ${ }^{27}$ which means that the regulations for particular activities might be in place but are not enforced giving the investors significant leeway to make their own decisions. This issue also applies to the decision making process on which projects receive funding, as often, that decision is made by donor organizations rather than the communities and views on priorities do not always align. ${ }^{28}$

\section{C14.4.3 Training and education}

In order to achieve sustainable tourism growth, ongoing training and education needs to be offered to enhance not just the private sector's but also the provincial government's capacity to develop, implement, monitor and enforce tourism plans, policies, frameworks and sustainability initiatives. The existing TVET centre in Lenakel for example could run tourism skills related trainings both for managers or owners of accommodation and activity operators, and for locals who wish to be employed in the sector. The University of South Pacific (USP) satellite campus could also offer some form of training certificates targeting those skills that are necessary for the sector, including sustainability issues. Increasing the local capacity and skill sets is often cited as an important area to make sure both direct and indirect benefits can flow from tourism activities and hence benefit a broader number of people. Identifying which skills sets are most needed and then targeting these

26 Joshua, J. (2017), 'Vanuatu signs strategic cooperation framework with Chinese Tourism group', Vanuatu Daily Post, 03-03-2017 (online), available at: www.pireport.org/ (04-06-2017).

27 Kuruppu, N. and Willie, R. (2015).

28 Betzold, C. (2015), 'Adapting to climate change in small island developing states', Climatic Change, volume 133, pp. 481-481. 
with training opportunities and budget commitments can ensure that at least the opportunities for local benefits increase.

\section{C14.4.4 Future global and local risks}

Major disruptions are a key factor that will make or break Tanna tourism, both globally (financial crises) and locally (volcanic eruptions and cyclones). This means that any tourism strategy or policy needs to consider disaster risk reduction and management specific practices and guideline for the sector, and also keep an eye on global trends that influence international tourism. At the global level, long term there may arise issues in relation to carbon taxes, changing social acceptability of air travel, and increase in oil prices.

One strategy to negate this would be to use the 'windfall' of tourism over the next decade or so to harness this growth for infrastructure development (e.g., sewage plants, solar electricity etc.) but simultaneously think about how other livelihoods can be developed to thrive after or independent of tourism. All of these issues therefore need to be wrapped up in the broader context of sustainability, including what 'sustainability' really means in the Tannese context. 